\title{
Yeast-mycelial dimorphism of haploid and diploid strains of Ustilago maydis
}

\author{
Jose Ruiz-Herrera, ${ }^{1,2}$ Claudia G. León, ${ }^{2}$ Lorenzo Guevara-Olvera ${ }^{2}$ and \\ Alfonso Cárabez-Trejo 3
}

Author for correspondence: Jose Ruiz-Herrera. Tel: +52 462 51600. Fax: +52 46251282.

\author{
1,2 Departamentos de \\ Genética y Biología \\ Molecular ${ }^{1}$ and Ingeniería \\ Genética (Unidad \\ Irapuato)2 ${ }^{2}$ Centro de \\ Investigación y de \\ Estudios Avanzados del \\ IPN, Irapuato, Gto, \\ Mexico \\ 3 Departamento de \\ Histología, Universidad \\ Nacional de México, \\ México, DF, Mexico
}

\begin{abstract}
Control of the pH of liquid synthetic culture media made possible mycelial growth of both diploid and haploid strains of Ustilago maydis. Whereas at neutral pH the fungus grew as a homogeneous population of budding yeastlike cells (sporidia), at acid pH it developed in the mycelial form. Mycelial cells appeared branched and narrower than yeast cells. Cell morphology was affected by the carbon and nitrogen sources. When the culture medium was removed continuously or intermittently, very long, filamentous cells were formed. Colonies of haploid strains developed aerial mycelium (' fuzz' morphology) on acid solid medium. Null $b, b W$, and bE mutants behaved in the same way as haploid wild-type strains. It is suggested that growth at low pH overcomes the control processes governed by heterologous bE and bW loci.
\end{abstract}

\section{INTRODUCTION}

Ustilago maydis is the agent responsible for corn smut, a disease with a worldwide distribution, which under some conditions may cause severe economical losses. This hemibasidiomycete displays a complex life-cycle which requires the host in order to be completed (see reviews by Christensen, 1963; Holliday, 1974). In its saprophytic phase, the fungus grows in the form of haploid, budding, yeast-like cells (sporidia). Sporidia of opposite matingtypes are able to fuse and give rise to the dikaryote which is the infective phase of the fungus. In host tissues, $U$. maydis grows in the form of mycelium, which eventually septates to form teliospores (also called chlamydospores). At this stage, karyogamy occurs. Millions of dark teliospores fill the galls characteristic of the disease. After germination of teliospores to form promycelium, meiosis and mitosis occur with the formation of four (or more) basidiospores originating from the septate cells of the promycelium. Basidiospores reproduce by budding, starting the life-cycle again. Evidence was presented by Rowell $(1955 a, b)$ that the sexual reaction of the fungus was controlled by two factors, now called $a$ and $b$, the first with two alleles and the second with multiple alleles. Only mating of haploids with different $a$ and $b$ loci results in pathogenicity. It has been further demonstrated that the $a$ locus governs mating and cell fusion (Trueheart \& Herskowitz, 1992). The two alleles of the $a$ locus have been cloned, and it has been demonstrated that they are idiomorphs (Froelinger \& Leong, 1991; Bolker et al., 1992). Each allele encodes the synthesis of a pheromone and the receptor for the mating factor synthesized by the opposite partner (Bolker et al., 1992). The $b$ locus controls filamentous growth and pathogenicity independently of the $a$ locus (Kronstad \& Leong, 1990; WangemannBudde \& Schauz, 1991). Several alleles of the $b$ locus have been cloned. Each one of them consists of two separate genes which are transcribed divergently, designated $b E$ and $b W$. They code for two different polypeptides, 410 and 626 amino acids in length, respectively. Both polypeptides contain a central homeodomain that separates a variable domain, and a constant region with over $90 \%$ homology among the different corresponding alleles (Kronstad \& Leong, 1990; Schulz et al., 1990; Banuet, 1992). Pathogenicity requires the presence of heterozygous $b E$ and $b W$ genes. It has been suggested that the protein products associate in the form of heterologous aggregates which switch on the genes responsible for the phenotype (Gillissen et al., 1992). Nevertheless, the means by which so many different possible aggregates are active remains unknown.

Transient mycelial growth is obtained when two compatible haploid strains are mixed on solid complex medium. This reaction, named 'fuzz' after the appearance of the aerial mycelium, is a useful test for mating compatibility. However no mycelial growth has been obtained in liquid culture. The possibility of reproducing the dimorphic transition under these conditions is extremely attractive, since it may allow a detailed analysis of the factors involved in the process and the reactions that take place in its initial periods. In addition the possibility 
of obtaining mutants affected at selected steps would then be feasible. These considerations prompted us to search for conditions which induce the dimorphic transition in U. maydis, using the rationale behind dimorphic systems in other fungi.

\section{METHODS}

Strains. The following strains of $U$. maydis were used in this study: FB1 $\left(a_{1} b_{1}\right), \mathrm{FB} 2\left(a_{2} b_{2}\right), \mathrm{D} 12\left(a_{1} b_{1} / a_{2} b_{2}\right)$, kindly provided by Dr Flora Banuet, University of California, San Francisco, $\mathrm{USA}$; and RK1447 $\left(a_{1} b^{-}\right), \operatorname{RK} 1723\left(a_{1} b W_{2}\right), \operatorname{RK} 1662\left(a_{1} b E_{2}\right)$, $\operatorname{RK} 1725\left(a_{1} b W_{1}\right)$ and RK1607 $\left(a_{1} b E_{1}\right)$, kindly provided by Dr Jörg Kamper, Institut für Genetik und Mikrobiologie der Universtät München, Germany.

Culture media and culture conditions. Strains were maintained at $-70{ }^{\circ} \mathrm{C}$ in $50 \%(\mathrm{v} / \mathrm{v})$ glycerol. They were transferred to liquid complex medium (Holliday, 1961), and shaken at $28^{\circ} \mathrm{C}$ for $2-3 \mathrm{~d}$. These cultures were used as inoculum for all subsequent experiments. Colony growth was observed on plates of solid mating medium containing $1 \%(\mathrm{w} / \mathrm{v}$ ) charcoal (Holliday, 1974), or on charcoal-containing synthetic medium (Holliday, 1974) maintained at a $\mathrm{pH}$ of either $7 \cdot 0$ or $3 \cdot 0$. Drops of liquid cultures at the end of exponential phase were placed on the plates. Alternatively, inoculum was streaked over the plates. After $24-48 \mathrm{~h}$ at $25^{\circ} \mathrm{C}$, the occurrence of the fuzz phenotype was recorded.

Mycelial development in liquid culture. The normal protocol (unless otherwise described) was as follows. Strains were grown for $24 \mathrm{~h}$ in liquid complex medium. The cells were recovered by centrifugation, washed twice with sterile distilled water and resuspended in the original volume of sterile distilled water. The cell suspensions were shaken at $28^{\circ} \mathrm{C}$ for about $3 \mathrm{~h}$, until most cells appeared unbudded. They were recovered by centrifugation, washed, resuspended in sterile distilled water and maintained at $4{ }^{\circ} \mathrm{C}$. They were used as experimental inoculum over a period not longer than $48 \mathrm{~h}$. Cell suspensions $\left(5 \times 10^{5}\right.$ cells $\mathrm{ml}^{-1}$ ) were used to inoculate synthetic medium (Holliday, 1961) maintained at $30^{\circ} \mathrm{C}$. The cultures were then incubated at $28^{\circ} \mathrm{C}$ on a shaker $(200$ r.p.m.). In media with an initial pH of $7 \cdot 0$, the cells developed as a homogeneous population of budding yeast-like cells. When the initial $\mathrm{pH}$ of the medium was reduced to $3 \cdot 0$, almost the whole population grew in the form of mycelium.

Light microscopy. Cells and colony sections were observed in non-stained preparations by interferential phase contrast microscopy, or stained with cotton blue and observed under bright field optics. For quantitative determinations, not less than 300 cells were counted.

Electron microscopy. Cells were fixed with $1 \%(\mathrm{v} / \mathrm{v})$ glutaraldehyde in cacodylate buffer, $\mathrm{pH} 7 \cdot 0$. They were washed with cacodylate buffer, post-fixed with $2 \%$ (w/v) osmium tetroxide, then washed and dehydrated in a graded acetone series. For transmission electron microscopy (TEM) cells were embedded in Epon-Araldite (Mollenhauer, 1964). Silver interference colour sections were collected on copper grids coated with formvar and carbon, and post-stained with lead citrate (Reynolds, 1963). For scanning electron microscopy (SEM), the dehydrated cells were mounted on specimen holders and coated with gold.

Miscellaneous. Cell numbers were estimated from the optical density at $650 \mathrm{~nm}$ using a calibration curve relating the two parameters. To measure cell growth, samples of the cultures were centrifuged at 3000 r.p.m. Sedimented cells were washed twice with distilled water and the protein content was de- termined by the Lowry method. In order to measure acidification of the solution by cell suspensions, the cells were normally incubated in $0.14 \mathrm{M} \mathrm{KCl}$ in a jacketed vessel. The temperature was $28^{\circ} \mathrm{C}$ and volume $2 \mathrm{ml}$. The cells were stirred and a stream of $\mathrm{CO}_{2}$-free air was continuously sparged into the suspension. Changes in $\mathrm{pH}$ were recorded with a $\mathrm{pH}$ meter coupled to a recorder.

Unless otherwise indicated, data reported are representative results from at least three different experiments.

\section{RESULTS}

Different stimuli induce the yeast-to-mycelial transition, and vice versa, in dimorphic fungi. These include changes in temperature, for example in Histoplasma capsulatum (Kobayashi et al., 1985) and Paracoccidioides brasiliensis (San Blas \& San Blas, 1985); high $\mathrm{CO}_{2}$ tension or anaerobiosis (Mucor spp., Bartnicki-Garcia, 1963); nature of the carbon source (Yarrowia lipolytica, Rodriguez \& Dominguez, 1984); and $\mathrm{pH}$ changes (Candida albicans, Soll, 1985). We made a systematic study to determine whether any of these environmental factors induced mycelial growth in $U$. maydis. Our results were negative. Nevertheless we found that in complex medium, $U$. maydis decreased the initial $\mathrm{pH}$, which was around neutral, to values below 3.0 . In some of these cultures we observed the appearance of long and distorted cells which, although not clearly mycelial, suggested a more polarized type of growth. In C. albicans it has been reported that a starvation period and a heat shock induce mycelial growth when the cells are further incubated at $37^{\circ} \mathrm{C}$. Similar results were obtained with Y. lipolytica (Guevara-Olvera et al., 1993). We thus subjected cells of a diploid strain of $U$. maydis (D12) to a starvation period and a heat shock in synthetic medium maintained at $\mathrm{pH} 3 \cdot 0$. Under these conditions we obtained an almost homogeneous population of irregular and branched mycelial cells (Fig. 1a, c). Conversely, normal budding sporidia developed when the initial $\mathrm{pH}$ of the medium was adjusted to $7 \cdot 0$ (Fig. $1 \mathrm{~b}, \mathrm{~d}$ ). Of particular interest was the observation that not only diploid strains, but also haploid ones (FB1 and FB2), responded similarly. Most of the subsequent experiments were done with strain FB2.

Cell sections are shown in Fig. 1(e) (mycelium) and 1(f) (yeast). Mycelium contained numerous mitochondria which showed well-developed cristae and appeared variable in shape (Fig. 2b). The presence of large amounts of glycogen was also noticeable (Fig. 1e). Nuclei were very large, and with conspicuous peri-nuclear nucleoli (Figs 1f, 2a).

Mycelial growth was noticed after 5-6 h of incubation, and reached a proportion of $60 \%$ after $12 \mathrm{~h}$ (Fig. 3). In older cultures ( $24 \mathrm{~h}$ or more), the central portion of the mycelium, corresponding to the original mother cell, developed septa which separated wide, rounded cells (Fig. 2c, d). This type of mycelial growth is not strictly different from the contorted mycelium observed in the host, which appears divided by septa, and later on gives rise to teliospores (Christensen, 1963). In sections, these rounded cells appeared separated by a thick cell wall, and full of what appeared to be lipid inclusions (Fig. 2f). 

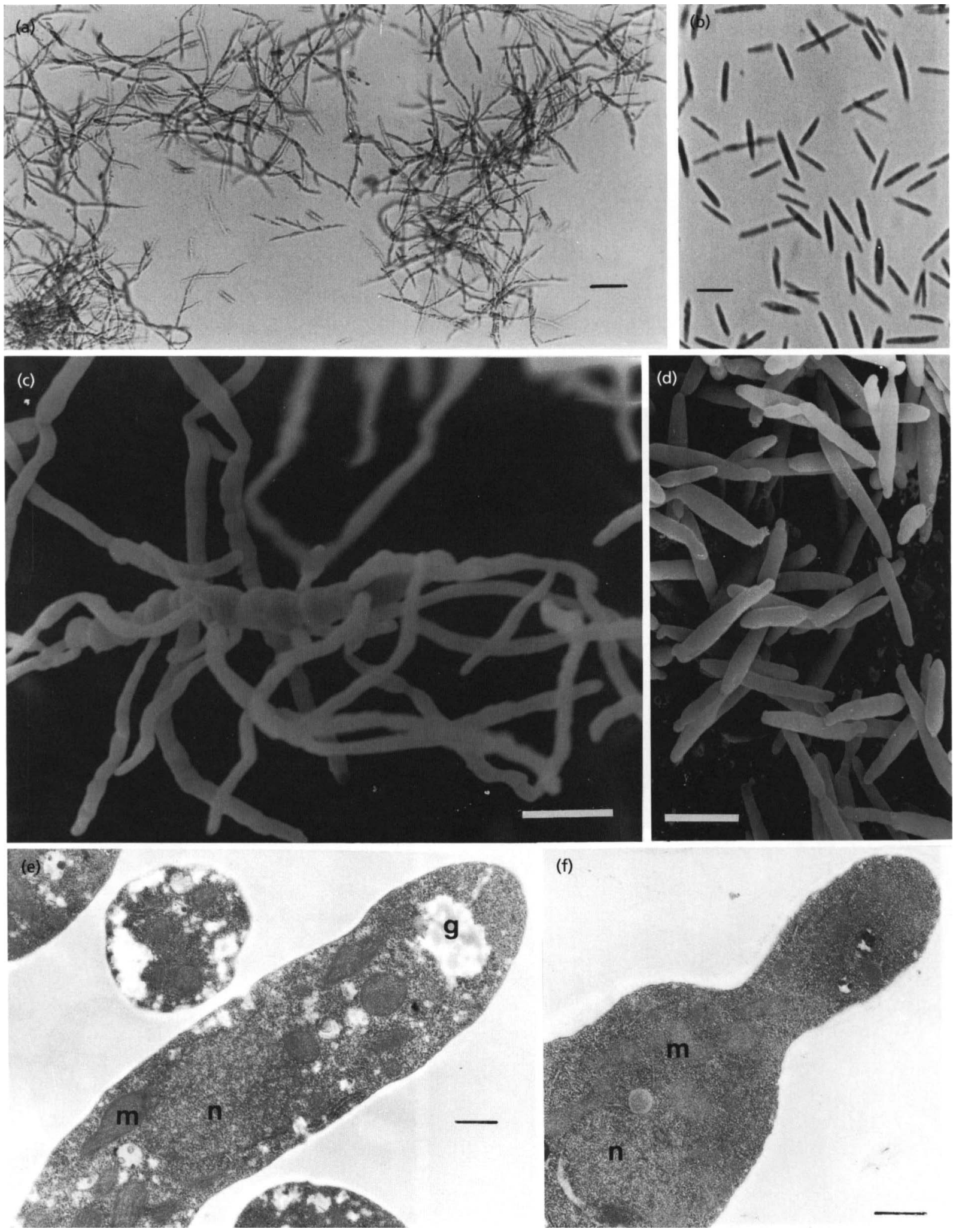

Fig. 1. Morphology of mycelial and yeast-like cells of $U$. maydis. (a, c) Mycelial growth of diploid strain D12 in synthetic medium, pH 3.0; (b, d) yeast-like growth of the same strain at pH 7.0; (e) median section of a mycelial cell; (f) median section of a budding yeast-like cell. $(a, b)$ Cells stained with cotton blue, bright field optics; $(c, d)$ scanning electron micrographs; $(e, f)$ transmission electron micrographs. g, Glycogen granules; $m$, mitochondria; $n$, nuclei. Bars: (a) $20 \mu \mathrm{m}$; (b, c, d) $10 \mu \mathrm{m} ;(e, f) 0.5 \mu \mathrm{m}$. 

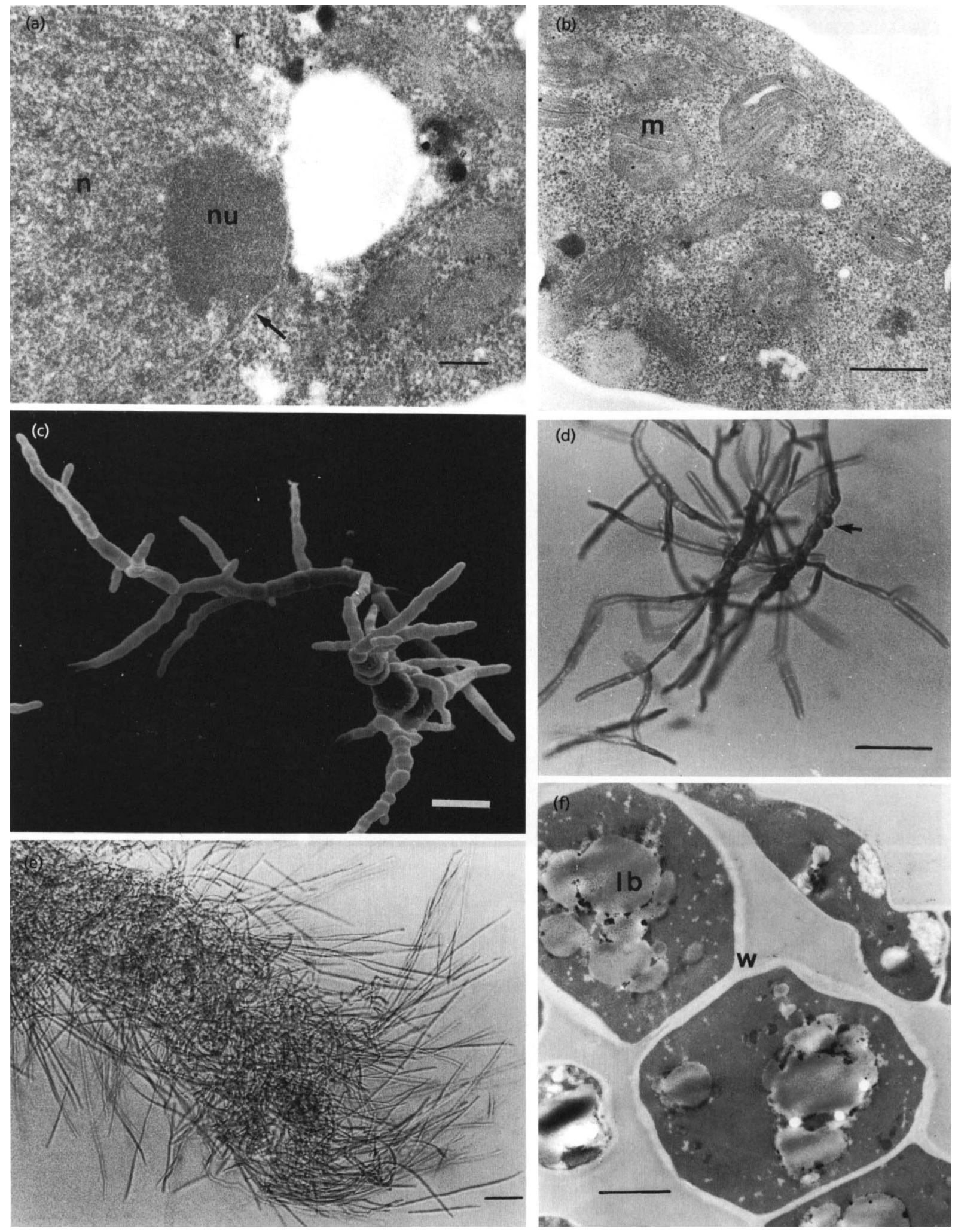

Fig. 2. Mycelial growth of haploid strain FB2 of $U$. maydis. $(a, b)$ Sections of mycelial cells. $m$, Mitochondria; $n$, nucleus; nu, nucleolus. The double nuclear membrane is marked with an arrow. (c, d, f) Enlargement and rounding of central cells (arrow), and development of thick septa; lb, lipid bodies; w, cell wall. (e) Large slender mycelium obtained at pH 3.0 in a succinate-containing medium. $(a, b, f)$ Transmission electron micrographs; (c) scanning electron micrograph; (d, e) cells stained with cotton blue, bright field optics. Bars: (a) $0.2 \mu \mathrm{m}$; (b) $0.5 \mu \mathrm{m}$; (c) $10 \mu \mathrm{m}$; (d, e) $20 \mu \mathrm{m}$; (f) $1 \mu \mathrm{m}$. 


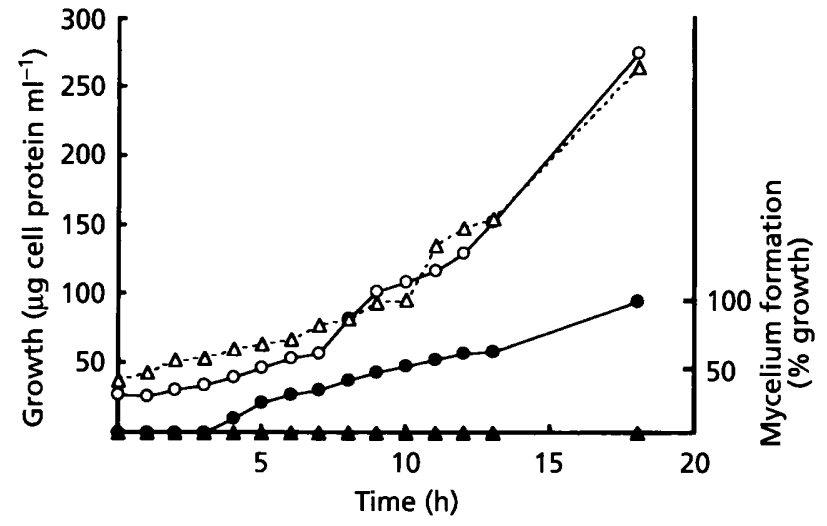

Fig. 3. Growth of and mycelium formation by $U$. maydis. Strain FB2 was inoculated into synthetic medium containing $1 \%$ glucose and $0.3 \% \mathrm{NH}_{4} \mathrm{NO}_{3}$. At the times indicated samples were recovered and either fixed in formaldehyde before examination of morphology (filled symbols) or used for determination of growth (open symbols). $\mathrm{O}$ and $\boldsymbol{Q}, \mathrm{pH} 3 ; \Delta$ and $\boldsymbol{\Delta}, \mathrm{pH}$.

Table 1. Effect of initial pH on dimorphism of $U$. maydis

Strain FB2 was grown for $18 \mathrm{~h}$ in synthetic medium containing $1 \%$ glucose and $0.3 \% \mathrm{NH}_{4} \mathrm{NO}_{3}$. Data are representative of three different experiments

\begin{tabular}{|cccc|}
\hline $\begin{array}{l}\text { Initial } \\
\mathbf{p H}\end{array}$ & $\begin{array}{c}\text { Final } \\
\mathbf{p H}\end{array}$ & $\begin{array}{c}\text { Growth } \\
\left(\boldsymbol{\mu} \text { g protein } \mathbf{~ m i}^{-\mathbf{1}}\right)\end{array}$ & $\begin{array}{c}\text { Proportion } \\
\text { in mycelial } \\
\text { phase (\%) }\end{array}$ \\
\hline $1 \cdot 0$ & $1 \cdot 50$ & 10 & 79 \\
$2 \cdot 0$ & $2 \cdot 28$ & 31 & 74 \\
$3 \cdot 0$ & $2 \cdot 54$ & 157 & 82 \\
$4 \cdot 0$ & $2 \cdot 62$ & 97 & 73 \\
$5 \cdot 0$ & $2 \cdot 52$ & 108 & 70 \\
$6 \cdot 0$ & $2 \cdot 47$ & 122 & 0 \\
$7 \cdot 0$ & $2 \cdot 75$ & 198 & 0 \\
\hline
\end{tabular}

Variations in the original $\mathrm{pH}$ of synthetic media containing $\mathrm{NH}_{4} \mathrm{NO}_{3}$ as nitrogen source demonstrated that a value around 3 was the optimum for mycelial growth (Table 1). Above this value, mycelial growth decreased, whereas at lower $\mathrm{pH}$ values total growth was severely reduced. Interestingly, $U$. maydis showed two $\mathrm{pH}$ optima for growth: 3 and 7 . Another important observation was that when initial $\mathrm{pH}$ values of 6 or 7 were used, the cells grew in a yeast-like form even though the $\mathrm{pH}$ subsequently fell to less than 3 (data not shown).

Nitrogen source was an important factor for mycelial growth (Table 2). Optimal results were obtained when $\mathrm{NH}_{4} \mathrm{NO}_{3}$ was used. In the presence of other ammonium salts and complex nitrogen sources, the proportion of mycelial cells decreased, and they appeared shorter and less branched. When $\mathrm{KNO}_{3}$ was used as nitrogen source, no mycelial growth was obtained, and the cells grew in a yeast-like form. Contrary to the results with ammonium salts, $\mathrm{pH}$ increased from 3.0 to almost 6.0 . Also, in contrast to the extreme acidification that occurred in cultures containing $\mathrm{NH}_{4} \mathrm{NO}_{3}$ as nitrogen source (see above), in cultures containing $\mathrm{KNO}_{3}$ the $\mathrm{pH}$ was maintained between 6 and 7. Interestingly, no growth was obtained when ammonium acetate was used as nitrogen source at $\mathrm{pH} \mathrm{3.0.} \mathrm{This} \mathrm{result} \mathrm{agrees} \mathrm{with} \mathrm{previous}$ observations with $U$. maydis ATCC 11427 (PRL 119; NRRL 2321) (Kurz \& Ericson, 1962). However, ammonium acetate was a good nitrogen source at $\mathrm{pH} 7 \cdot 0$. We showed that this phenomenon was due to toxicity of acetic acid. Acetic acid $(0.04 \mathrm{M})$, or ammonium, sodium or potassium acetate were toxic at $\mathrm{pH} 3$, but had almost no effect on cell growth at $\mathrm{pH} 7$ in $\mathrm{NH}_{4} \mathrm{NO}_{3}$ - or $\mathrm{KNO}_{3}$ containing synthetic media.

Of the carbon sources tested, all gave similar results with regard to the dimorphic transition, although citrate, xylose and sorbitol were only poorly utilized (Fig. 4). Our data contrast with those of Kurz \& Ericson (1962), who reported that $U$. maydis ATCC 11427 efficiently utilized xylose and sorbitol as sole carbon sources. Although growth yield in succinate was about $20 \%$ of that obtained in the presence of glucose, very smooth and regular mycelial cells were formed with this carbon source (Fig. $2 \mathrm{e})$. High concentrations of glucose (5 and $10 \%)$ reduced mycelial growth, and the cells appeared shorter and less branched. A consistent observation was that large inocula and low aeration reduced mycelial development.

Incubation of either yeast-like cells or mycelium in water or a saline solution $(0 \cdot 14 \mathrm{M} \mathrm{NaCl}$ or $\mathrm{KCl})$, caused rapid

Table 2. Effect of nitrogen source on dimorphism of $U$. maydis

Strain FB2 was grown for $18 \mathrm{~h}$ in synthetic medium, $\mathrm{pH} 3 \cdot 0$, containing $1 \%$ glucose and $0 \cdot 3 \%$ of the nitrogen sources indicated. No growth, yeast or mycelial, occurred when ammonium acetate was used as a nitrogen source. Data are averages of two experiments whose differences did not exceed $15 \%$.

\begin{tabular}{|c|c|c|c|c|}
\hline $\begin{array}{l}\text { Nitrogen } \\
\text { source }\end{array}$ & $\begin{array}{c}\text { Final } \\
\text { pH }\end{array}$ & $\begin{array}{c}\text { Growth } \\
\left(\mu \mathrm{g} \text { protein } \mathrm{ml}^{-1}\right)\end{array}$ & $\begin{array}{c}\text { Proportion } \\
\text { in mycelial } \\
\text { phase }(\%)\end{array}$ & Morphology \\
\hline $\mathrm{NH}_{4} \mathrm{NO}_{3}$ & $2 \cdot 74$ & 173 & 100 & Large, branched mycelium \\
\hline$\left(\mathrm{NH}_{4}\right)_{2} \mathrm{SO}_{4}$ & $2 \cdot 55$ & 168 & 73 & Short mycelium \\
\hline Casamino acids & $2 \cdot 42$ & 628 & 68 & Short mycelium \\
\hline $\mathrm{KNO}_{3}$ & $5 \cdot 70$ & 147 & 0 & Budding yeast cells \\
\hline
\end{tabular}




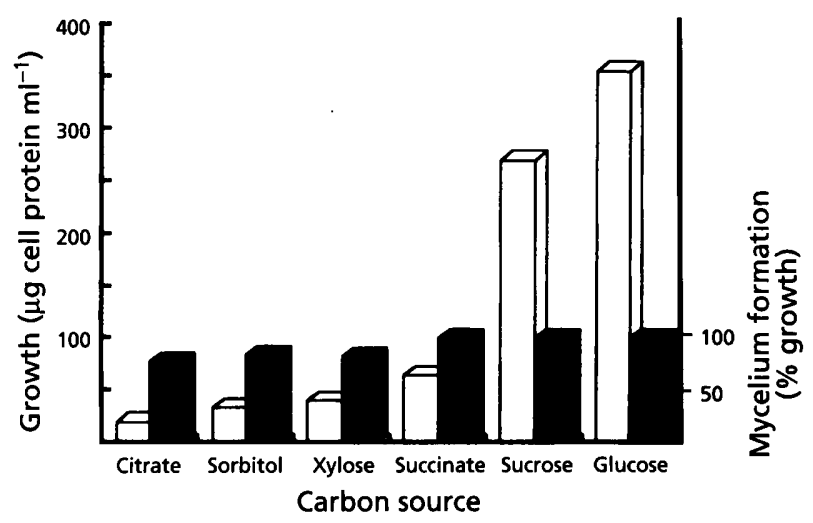

Fig. 4. Effect of carbon sources on growth $(\square)$ and mycelium formation ( $\square$ ) by $U$. maydis. Strain FB2 was grown for $18 \mathrm{~h}$ in synthetic medium, $\mathrm{pH} 3.0$, with $0.3 \%$ ammonium nitrate and the carbon sources indicated (1\%). Citrate and succinate were provided as sodium salts.

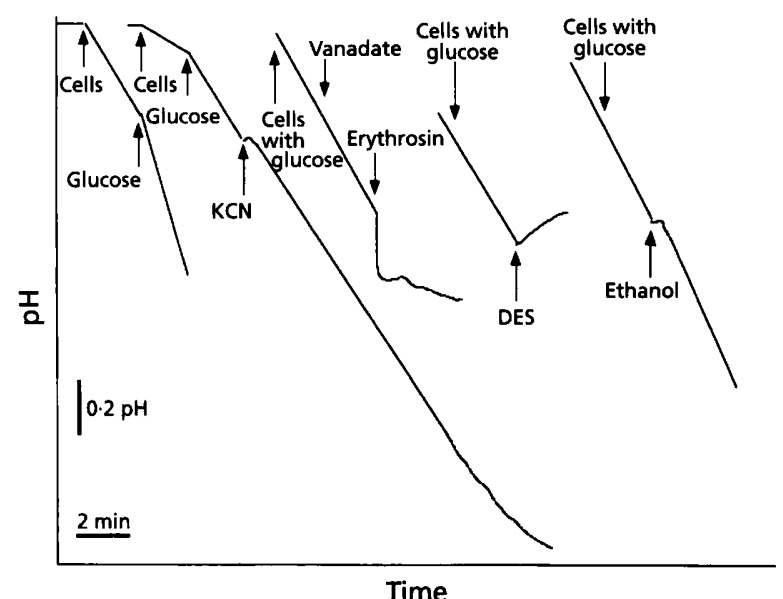

Fig. 5. Acidification of suspending solution by $U$. maydis. Cells of strain FB2 were incubated in $0.14 \mathrm{M} \mathrm{KCl}$ as described in Methods. Mycelial cell suspensions $(20 \mu \mathrm{g}$ protein), $0.5 \%$ glucose, $2 \mathrm{mM} \mathrm{KCN}, 200 \mu \mathrm{M}$ sodium vanadate, $50 \mu \mathrm{M}$ erythrosin in ethanol, $100 \mu \mathrm{M}$ diethylstylboestrol in ethanol (DES) or $2 \%$ ethanol were added at the times indicated by arrows. $\mathrm{pH}$ was recorded continuously.

acidification. Representative results are shown in Figs 5 and 6. Glucose addition stimulated the rate of acidification (Fig. 5). KCN had no immediate effect on acidification rate and this decreased only gradually after prolonged incubation (Fig. 5). By contrast, acidification was completely halted by the addition of $100 \mu \mathrm{M}$ diethylstilboestrol, and inhibited by more than $90 \%$ by $50 \mu \mathrm{M}$ erythrosin $\mathrm{B}$, whereas $200 \mu \mathrm{M}$ sodium vanadate was without effect, probably due to permeability problems (Fig. 5). Acidification rate was increased by addition of $\left(\mathrm{NH}_{4}\right)_{2} \mathrm{SO}_{4}$ and reduced in the presence of $\mathrm{KNO}_{3}$ (Fig. 6).

In order to determine whether mycelial development was restricted when the medium became exhausted, cultures were prepared where the medium was changed every

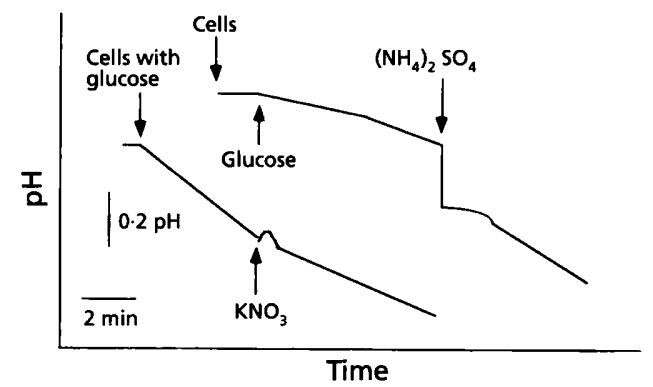

Fig. 6. Effect of $\mathrm{NH}_{4}^{+}$or $\mathrm{NO}_{3}^{-}$ions on acidification of suspending solution by $U$. maydis. Cells of strain FB2 were incubated in $0.14 \mathrm{M} \mathrm{KCl}$ as described in Methods. Mycelial cell suspensions $\left(10 \mu \mathrm{g}\right.$ protein), $0.075 \% \mathrm{KNO}_{3}$, or $0.075 \%\left(\mathrm{NH}_{4}\right)_{2} \mathrm{SO}_{4}$, were added at the times indicated by arrows.

$12 \mathrm{~h}$. Alternatively, cells were inoculated into a dialysis bag inside a $500 \mathrm{ml} \mathrm{microfermenter.} \mathrm{A} \mathrm{continuous} \mathrm{stream}$ of air was bubbled inside the dialysis bag, and the medium was removed continuously at a rate of $20 \mathrm{ml} \mathrm{h}^{-1}$. In both cases very long and regular filaments were obtained (not shown).

Mycelial growth was freely reversible at any stage. Cells transferred after up to $12 \mathrm{~h}$ from cultures at $\mathrm{pH} 3$ to media at $\mathrm{pH} 7$ grew in a yeast-like form. Conversely, a yeast-tomycelial transition occurred only if cells were transferred to media at $\mathrm{pH} 3$ not later than $4 \mathrm{~h}$ after being inoculated into media at $\mathrm{pH}$. After this time, they continued growing in the yeast form.

Acid conditions not only induced mycelial growth in liquid cultures, but also on solid media. It is known that compatible mating strains and stable diploids produce aerial and vegetative mycelium on neutral solid media (Fig. 7b, f, i). This so-called 'fuzz' reaction is better observed in media containing charcoal. Under these same conditions haploid strains produce smooth colonies (Fig. 7a), and yeast-like growth (Fig. 7e). Conversely, in synthetic medium of $\mathrm{pH} 3.0$, mycelial colonies indistinguishable from those of diploid strains or compatible crosses were formed by haploid strains (Fig. 7d, g).

It is known that the $b$ locus is involved in mycelial growth of dikaryotic cells during the pathogenic phase of the fungus (Kronstad \& Leong, 1989; Wangemann-Budde \& Schauz, 1991; Banuet, 1992). We thus proceeded to test whether mycelial growth at an acid $\mathrm{pH}$ was also dependent on the $b$ locus. This was not the case: strains RK1447 $\left(a_{1} b^{-}\right)$, RK1723 $\left(a_{1} b W_{2}\right)$ and $\operatorname{RK} 1662\left(a_{1} b E_{2}\right)$ were all able to produce mycelial colonies on plates of acid medium (shown for RK1477 in Fig. 7c, h, i). It was also observed that the protocol described in Methods enabled all these strains to grow as mycelium in acid liquid medium in similar proportions to wild-type strains (Table 3).

\section{DISCUSSION}

$U$. maydis has been a classical model for genetic studies of a plant pathogen (Holliday, 1961, 1974). It is also a useful model for the study of the relationships existing between 

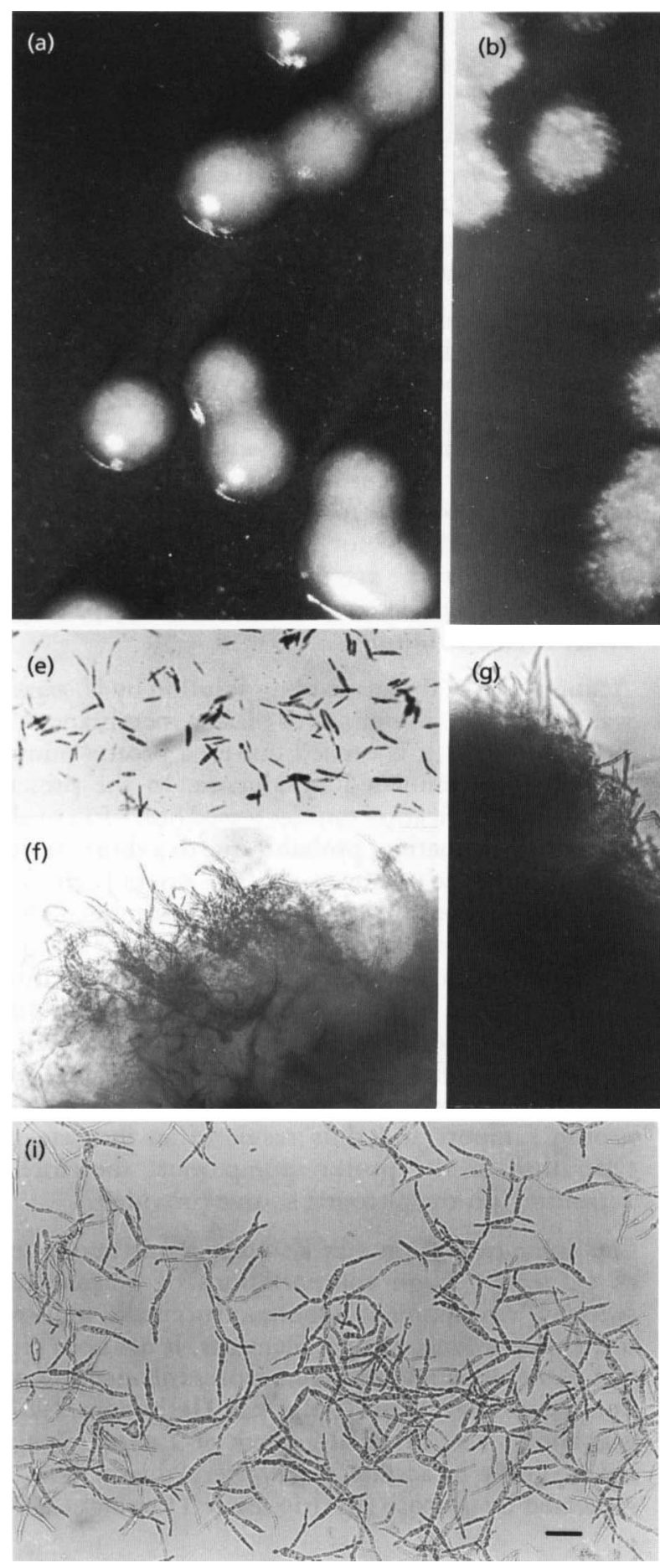

(g)
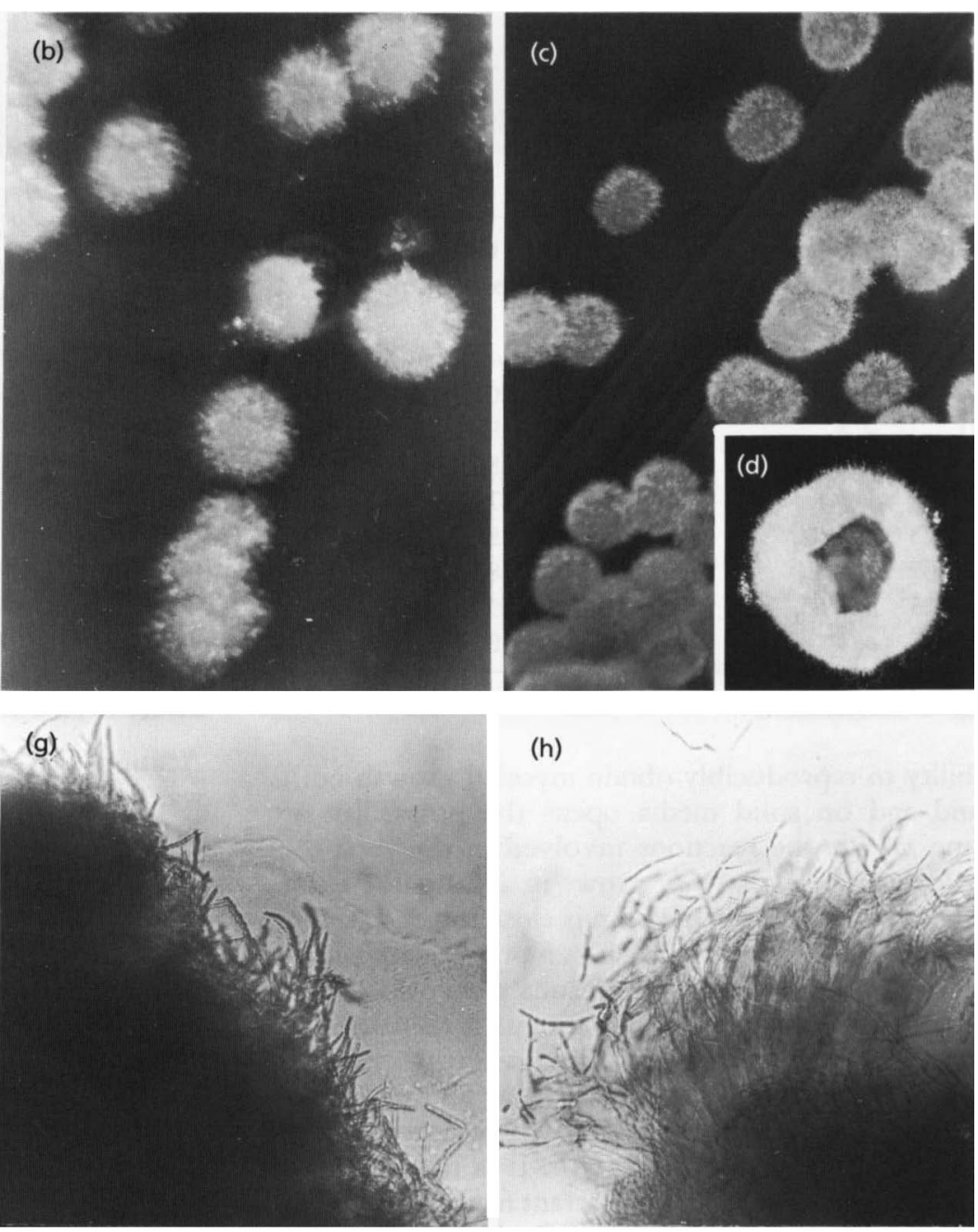

(h)

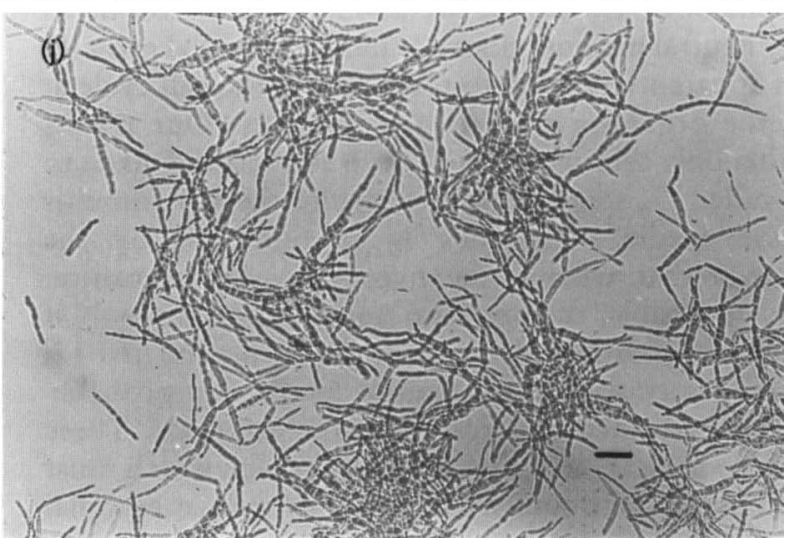

Fig. 7. Colony and cell morphology of $U$. maydis strains growing on solid media. Cells were streaked on synthetic media, $\mathrm{pH} 3.0$ or 7.0 , containing $1 \%$ activated charcoal and incubated at $25^{\circ} \mathrm{C}$ for $48 \mathrm{~h}$. Macroscopic and microscopic morphology was recorded. (a, b, c, d) Colonies of strains FB2 at pH 7.0, D12 at pH 7.0, RK1447 at pH 3.0 and FB2 at pH 3.0, respectively; (e) yeast-like cells of strain FB2 at pH 7.0; $(f, g, h)$ surface of colonies of strains D12 at pH 7.0, FB2 at pH 3.0 and RK1447 at pH 3.0, respectively; ( $i, j)$ mycelial cells of strains $D 12$ at $\mathrm{pH} 7.0$ and RK1447 at pH 3.0, respectively. $(e, f, g, h, i, j)$ Cells stained with cotton blue. Bars, $20 \mu \mathrm{m}$.

dimorphic transition and pathogenicity. Two separate phases may be recognized in the fungus: a haploid, saprophytic, yeast-like phase, and a dikaryotic, patho- genic, mycelial one. Unfortunately, mycelial growth of the dikaryotic phase may be obtained only transiently on solid media (the fuzz reaction). 
Table 3. Mycelial growth of different strains of $U$. maydis

Cells were grown in liquid synthetic medium, $\mathrm{pH} 3 \cdot 0$, following the protocol described in Methods. Data are means of four different experiments, $\pm s D$.

\begin{tabular}{|llll|}
\hline Strain & $\begin{array}{c}\text { Relevant } \\
\text { genotype }\end{array}$ & $\begin{array}{c}\text { Proportion } \\
\text { in mycelial } \\
\text { phase (\%) }\end{array}$ & $\begin{array}{c}\text { Growth } \\
\left(\boldsymbol{\mu} \text { g protein } \mathbf{~ m}^{-1} \text { ) }\right.\end{array}$ \\
\hline D12 & $a_{1} b_{1} / a_{2} b_{2}$ & $98 \cdot 3 \pm 1 \cdot 5$ & $201 \cdot 0 \pm 3 \cdot 9$ \\
FB1 & $a_{1} b_{1}$ & $74 \cdot 1 \pm 7 \cdot 7$ & $190 \cdot 1 \pm 7 \cdot 8$ \\
FB2 & $a_{2} b_{2}$ & $78 \cdot 5 \pm 4 \cdot 0$ & $185 \cdot 5 \pm 3 \cdot 9$ \\
RK1662 & $a_{1} b E_{2}$ & $81 \cdot 1 \pm 7 \cdot 0$ & $179 \cdot 1 \pm 7 \cdot 3$ \\
RK1723 & $a_{1} b W_{2}$ & $80 \cdot 5 \pm 7 \cdot 6$ & $189 \cdot 7 \pm 3 \cdot 0$ \\
RK1607 & $a_{1} b E_{1}$ & $76 \cdot 5 \pm 8 \cdot 0$ & $183 \cdot 3 \pm 1 \cdot 9$ \\
RK1725 & $a_{1} b W_{1}$ & $79 \cdot 6 \pm 7 \cdot 9$ & $197 \cdot 9 \pm 14 \cdot 0$ \\
RK1447 & $a_{1} b^{-}$ & $80 \cdot 6 \pm 6 \cdot 6$ & $189 \cdot 1 \pm 6 \cdot 1$ \\
\hline
\end{tabular}

Our ability to reproducibly obtain mycelial growth both in liquid and on solid media opens the possibility of analysing in vitro the reactions involved in the yeast-tomycelial transition. U. maydis grows in a yeast-like form when the initial $\mathrm{pH}$ of the medium is close to neutral, and in a mycelial form if it is acid, with an optimum at $\mathrm{pH} 3$. It is noteworthy that contrasting results were obtained in the case of Candida albicans. If this fungus is cultivated at an acid $\mathrm{pH}$ it grows in the yeast form, whereas a neutral $\mathrm{pH}$ favours mycelial growth (Soll, 1985). To our knowledge, U. maydis is the only fungal dimorphic system where an acid $\mathrm{pH}$ induces mycelial growth. It is important to recall that the initial $\mathrm{pH}$ is the important factor in mycelial development of $U$. maydis. Metabolic acidification of an initially neutral medium does not induce mycelial growth. This is apparently related to the phase in the cell cycle at which the organism receives the stimulus. Our results show that only cells which have been starved and taken to the so-called $\mathrm{G}_{0}$ stage are responsive to the $\mathrm{pH}$ stimulus in liquid media. This idea is strengthened by the observation that, whereas the mycelial-to-yeast transition is freely reversible, the opposite transition occurs only if yeast cells are transferred to acid media within the first $4 \mathrm{~h}$ after being inoculated into neutral media, i.e. probably before they advance significantly in the cell cycle. These results also indicate that low $\mathrm{pH}$ is a stimulus which must be maintained continuously in order to induce mycelial growth.

A mechanism by which $\mathrm{pH}$ controls dimorphism in $U$. maydis can only be proposed based on the results obtained in other systems. It has been reported that inhibition of mycelial growth after transfer of $C$. albicans cells from $\mathrm{pH} 7$ to $\mathrm{pH} 4$ was accompanied by changes in the cytoskeleton (Yokoyama et al., 1994). Long microfilaments and apical actin granules characteristic of hyphal growth disappeared after transfer to acidic conditions. However, no change in microtubule structure or distribution was observed under those conditions. Using subtractive $\mathrm{cDNA}$ libraries from $C$. albicans, a gene whose expression depended on $\mathrm{pH}$ changes has been cloned and analysed (Fonzi et al., 1993). This gene, named PHR1, is expressed at $\mathrm{pH}$ values near neutral, but not in acid conditions. The predicted protein which it encodes shows high homology $(56 \%)$ with a glycoprotein from Saccharomyces cerevisiae, gp115, which is regulated during the cell cycle. Disruption of PHR 1 in C. albicans abolished its capacity to grow in mycelial form. It is possible that a similar mechanism exists in $U$. maydis.

The fact that $\mathrm{pH}$-induced dimorphism is independent of diploidy and $b$ locus regulation does not indicate that it is a separate phenomenon to the mycelial growth displayed by the pathogenic phase of the fungus. The most likely possibility is that the $\mathrm{pH}$ response bypasses the reaction dependent on $b$ locus products, and that the further reactions responsible for mycelial development depend on genes which do not require the diploid state. It is unfortunate that the extreme $\mathrm{pH}$ conditions necessary for mycelial growth impair the analysis of pathogenicity under such conditions.

Acidification of the suspending solution by $U$. maydis cells was sensitive to inhibitors of plasma membrane ATPase, suggesting that it is carried out by a proton pump. The process was stimulated by glucose. In the presence of $\mathrm{KCN}$, the acidification rate decreased only after prolonged periods of incubation, probably due to a shortage of ATP. Operation of the proton pump, and not only the intrinsic $\mathrm{pH}$ value, is probably involved in morphogenesis. $\mathrm{NH}_{4}^{+}$ ions, which are the best nitrogen source for mycelial development, are apparently taken up by a direct or indirect proton antiport mechanism, thus leading to a further decrease in external $\mathrm{pH}$. However $\mathrm{NO}_{3}^{-}$ions, which abolish the morphogenetic effect of low $\mathrm{pH}$, are probably transported by the direct or indirect action of a proton symport and thus result in an increase in $\mathrm{pH}$. Operation of the proton pump must therefore differ depending on the nitrogen source provided.

Catabolite repression may also play a role in dimorphism of $U$. maydis. High concentrations of glucose reduced mycelial development whereas succinate induced the formation of long, slender filaments. It has been reported that glucose and related sugars repress filamentous growth of C. albicans at acid pH (Pollack \& Hashimoto, 1987), and it is known that mycelial growth of Yarrowia lipolytica is induced only by acetate and $\mathrm{N}$-acetylglucosamine, and is repressed by glucose (Rodriguez \& Dominguez, 1984).

\section{ACKNOWLEDGEMENTS}

This work was partially supported by CONACYT (México). Thanks are given to Dr Flora Banuet from the University of California, San Francisco, for making available strains FB1, FB2 and D12; and Dr Jörg Kamper from the Institut für Genetik und Mikrobiologie der Universtät München for providing strains RK1447, RK1723, RK1662, RK1725 and RK1607.

\section{REFERENCES}

Banuet, F. (1992). Ustilago maydis, the delightful blight. Trends Genet 8, 174-180. 
Bartnicki-Garcia, S. (1963). Mold-yeast dimorphism of Mucor rouxii. Bacteriol Rev 27, 293-304.

Bolker, M., Urban, M. \& Kahman, R. (1992). The a mating-type locus of Ustilago maydis specifies cell signaling components. Cell 68, 441-450.

Christensen, J. J. (1963). Corn smut caused by Ustilago maydis. (American Phytopathological Society Monograph no. 2). St Paul, MN: American Phytopathological Society.

Fonzi, W. A., Saporito-Irwin, S., Chen, J. Y. \& Sypherd, P. (1993). Genetic basis for fungal dimorphism and pathogenicity in Candida albicans. In Dimorphic Fungi in Biology and Medicine, pp. 37-50. Edited by H. Vanden Bossche, F. C. Odds \& D. Kerridge. New York: Plenum Press.

Froelinger, E. H. \& Leong, S. A. (1991). The $a$ mating-type alleles of Ustilago maydis are idiomorphs. Gene 100, 113-122.

Gillissen, B., Bergemann, J., Sandmann, C., Schroeer, B., Bölker, M. \& Kahmann, R. (1992). A two-component regulatory system for self/non-self recognition in Ustilago maydis. Cell 68, 647-657.

Guevara-Olvera, L., Calvo-Mendez, C. \& Ruiz-Herrera, J. (1993). The role of polyamine metabolism in dimorphism of Yarrowia lipolytica. J Gen Microbiol 139, 485-493.

Holliday, R. (1961). The genetics of Ustilago maydis. Genet Res 2, 204-230.

Holliday, R. (1974). Ustilago maydis. In Handbook of Genetics, vol. 1, pp. 575-595. Edited by R. C. King. New York: Plenum Press.

Kobayashi, G. S., Medoff, G., Maresca, B., Sacco, M. \& Kumar, B. V. (1985). Studies on phase transition in the dimorphic pathogen Histoplasma capsulatum. In Fungal Dimorphism, with Emphasis on Fungi Pathogenic for Humans, pp. 69-91. Edited by P. J. Szaniszlo. New York: Plenum Press.

Kronstad, J. W. \& Leong, S. A. (1989). Isolation of two alleles of the $b$ locus of Ustilago maydis. Proc Natl Acad Sci USA 86, 978-982.

Kronstad, J. W. \& Leong, S. A. (1990). The $b$ mating-type locus of Ustilago maydis contains variable and constant regions. Genes \& Dev 4, 1384-1395.

Kurz, W. G. \& Ericson, L. E. (1962). Microbial production of amino acids. II. The influence of carbon and nitrogen sources and metal ions on growth of Ustilago maydis (DC.) $\mathrm{CDa}$, and on lysine and threonine production. Biotechnol Bioeng 4, 37-52.
Mollenhauer, H. H. (1964). Plastic embedding mixtures in electron microscopy. Stain Technol 39, 111-114.

Pollack, J. H. \& Hashimoto, T. (1987). The role of glucose in the $\mathrm{pH}$ regulation of germ-tube formation in Candida albicans. $J$ Gen Microbiol 133, 415-424.

Reynolds, E. S. (1963). The use of lead citrate at high $\mathrm{pH}$ as an electron opaque stain in electron microscopy. $J$ Cell Biol 17, 208-212.

Rodriguez, C. \& Dominguez, A. (1984). The growth and characteristics of Saccharomycopsis lipolytica: morphology and induction of mycelium formation. Can J Microbiol 11, 287-296.

Rowell, J. B. (1955a). Segregation of sex factors in a diploid line of Ustilago zeae induced by alpha radiation. Science 121, 304-306.

Rowell, J. B. (1955b). Functional role of compatibility factors and an in vitro test for sexual compatibility with haploid lines of Ustilago zeae. Phytopathology 45, 370-374.

San-Blas, F. \& San-Blas, G. (1985). Paracoccidioides brasiliensis. In Fungal Dimorphism with Emphasis on Fungi Pathogenic for Humans, pp. 93-120. Edited by P. J. Szaniszlo. New York: Plenum Press.

Schulz, B., Banuet, F., Dahl, M., Schlesinger, R., Schäfer, W., Martin, T., Herskowitz, I. \& Kahman, R. (1990). The $b$ alleles of $U$. maydis, whose combinations program pathogenic development, code for polypeptides containing a homeodomain-related motif. Cell 60, 295-306.

Soll, D. R. (1985). Candida albicans. In Fungal Dimorphism with Emphasis on Fungi Pathogenic for Humans, pp. 167-195. Edited by P. J. Szaniszlo. New York: Plenum Press.

Trueheart, J. \& Herskowitz, I. (1992). The a locus governs cytoduction in Ustilago maydis. J Bacteriol 174, 7831-7833.

Wangemann-Budde, M. \& Schauz, K. (1991). Intraspecific hybridization of Ustilago maydis haploids with compatible and incompatible mating type by electrofusion and genetic analysis of the fusion products. Exp Mycol 15, 159-166.

Yokoyama, K., Kaji, H., Nishimura, K. \& Miyaji, M. (1994). The role of microfilaments and microtubules during $\mathrm{pH}$-regulated morphological transition in Candida albicans. Microbiology 140, 281-287.

Received 3 May 1994; revised 20 October 1994; accepted 25 October 1994. 